\title{
Correction to: A validated single-cell-based strategy to identify diagnostic and therapeutic targets in complex diseases
}

Danuta R. Gawel ${ }^{1 \dagger}$, Jordi Serra-Musach ${ }^{1 \dagger}$, Sandra Lilja', Jesper Aagesen², Alex Arenas ${ }^{3}$, Bengt Asking ${ }^{4}$, Malin Bengnér ${ }^{5}$, Janne Björkander ${ }^{2}$, Sophie Biggs ${ }^{6}$, Jan Ernerudh ${ }^{7}$, Henrik Hjortswang ${ }^{8}$, Jan-Erik Karlsson ${ }^{2,9}$, Mattias Köpsen ${ }^{10}$, Eun Jung Lee ${ }^{1,11}$, Antonio Lentini ${ }^{16}$, Xinxiu Li $^{1}$, Mattias Magnusson ${ }^{6}$, David Martínez-Enguita ${ }^{10}$, Andreas Matussek ${ }^{12,13,14}$, Colm E. Nestor ${ }^{16}$, Samuel Schäfer ${ }^{1}$, Oliver Seifert ${ }^{15,16}$, Ceylan Sonmez ${ }^{10}$, Henrik Stjernman², Andreas Tjärnberg ${ }^{10}$, Simon Wu ${ }^{10}$, Karin Åkesson ${ }^{16,17}$, Alex K. Shalek ${ }^{18,19,20,21,22}$, Margaretha Stenmarker ${ }^{17,23}$, Huan Zhang ${ }^{1 *+}$, Mika Gustafsson $^{10+}$ and Mikael Benson ${ }^{1 *+}$

\section{Correction to: Genome Med 11, 47 (2019) https://doi.org/10.1186/s13073-019-0657-3}

It was highlighted that in the original article [1] there was an omission in the Funding section. This Correction article shows the correct Funding section.

\begin{abstract}
Author details
${ }^{1}$ Centre for Personalized Medicine, Linköping University, Linköping, Sweden. ${ }^{2}$ Department of Internal Medicine, Region Jönköping County, Jönköping, Sweden. ${ }^{3}$ Departament d'Enginyeria Informàtica i Matemàtiques, Universitat Rovira i Virgili, Tarragona, Spain. ${ }^{4}$ Department of Surgery, Region Jönköping County, Jönköping, Sweden. ${ }^{5}$ Office for Control of Communicable Diseases, Region Jönköping County, Jönköping, Sweden. ${ }^{6}$ Division of Rheumatology, Autoimmunity, and Immune Regulation, Department of Clinical and Experimental Medicine, Linköping University, Linköping, Sweden. ${ }^{7}$ Department of Clinical Immunology and Transfusion Medicine, Linköping University, Linköping, Sweden. ${ }^{8}$ Department of Gastroenterology and Department of Clinical and Experimental Medicine, Linköping University, Linköping, Sweden. ${ }^{9}$ Department of Medical and Health Sciences, Linköping University, Linköping, Sweden. ${ }^{10}$ Bioinformatics, Department of Physics, Chemistry and Biology, Linköping University, Linköping, Sweden.

${ }^{11}$ Department of Otorhinolaryngology, Yonsei University College of Medicine Seoul, South Korea. ${ }^{12}$ Clinical Microbiology, Region Jönköping County, Jönköping, Sweden. ${ }^{13}$ Division of Clinical Microbiology, Department of Laboratory Medicine, Karolinska Institute, Karolinska University Hospital Huddinge, Stockholm, Sweden. ${ }^{14}$ Karolinska University Laboratory, Karolinska
\end{abstract}

The original article can be found online at https://doi.org/10.1186/s13073 020-00732-7

* Correspondence: huan.zhang@liu.se; mikael.benson@liu.se

${ }^{\dagger}$ Danuta R. Gawel, Jordi Serra-Musach, Huan Zhang, Mika Gustafsson, and Mikael Benson contributed equally as first and last authors, respectively. ${ }^{1}$ Centre for Personalized Medicine, Linköping University, Linköping, Sweden Full list of author information is available at the end of the article
University Hospital, Solna, Sweden. ${ }^{15}$ Department of Dermatology and Venereology, Region Jönköping County, Jönköping, Sweden. ${ }^{16}$ Department of Clinical and Experimental Medicine, Faculty of Medicine and Health Sciences, Linköping University, Linköping, Sweden. ${ }^{17}$ Futurum - Academy for Health and Care, Department of Pediatrics, Region Jönköping County, Jönköping, Sweden. ${ }^{18}$ Institute for Medical Engineering and Science, Massachusetts Institute of Technology, Cambridge, MA, USA. ${ }^{19}$ Department of Chemistry, Massachusetts Institute of Technology, Cambridge, MA, USA.

${ }^{20}$ Koch Institute for Integrative Cancer Research, Massachusetts Institute of Technology, Cambridge, MA, USA. ${ }^{21}$ Broad Institute of MIT and Harvard, Cambridge, MA, USA. ${ }^{22}$ Ragon Institute of MGH, MIT and Harvard, Cambridge, MA, USA. ${ }^{23}$ Department of Pediatrics, Institution for Clinical Sciences, Göteborg, Sweden.

Published online: 28 April 2020

\section{Funding}

This work was supported by Nordforsk, Swedish Cancer Foundation grants 170542 and 15 0532; European Commission grant 305033; East Gothia Regional Funding; the Swedish Research Council grants 2015-02575, 201503495, and 2015-03807; Clinical Cancer Research, Jönköping, Sweden; and Torsten Söderberg Foundation.

\section{Reference}

1. Gawel, et al. A validated single-cell-based strategy to identify diagnostic and therapeutic targets in complex diseases. Genome Medicine. 2019;11:47. https://doi.org/10.1186/s13073-019-0657-3.

(C) The Author(s). 2020 Open Access This article is licensed under a Creative Commons Attribution 4.0 International License, which permits use, sharing, adaptation, distribution and reproduction in any medium or format, as long as you give appropriate credit to the original author(s) and the source, provide a link to the Creative Commons licence, and indicate if changes were made. The images or other third party material in this article are included in the article's Creative Commons licence, unless indicated otherwise in a credit line to the material. If material is not included in the article's Creative Commons licence and your intended use is not permitted by statutory regulation or exceeds the permitted use, you will need to obtain permission directly from the copyright holder. To view a copy of this licence, visit http://creativecommons.org/licenses/by/4.0/ The Creative Commons Public Domain Dedication waiver (http://creativecommons.org/publicdomain/zero/1.0/) applies to the data made available in this article, unless otherwise stated in a credit line to the data. 